\title{
ELOGIO DE LA MADRASTRA DE MARIO VARGAS LLOSA, UN RELATO MODERNISTA
}

\author{
POR \\ CONCEPCION REVERTE BERNAL \\ Universidad de Cádiz
}

\begin{abstract}
Il faut porter ses vices comme un manteau royal, sans hate. Comme une auréle qu'on ignore, dont on fait semblant de ne pas s'apercevoir.

Il n'y a que les êtres à vice dont le contour ne s'estompe dans la boue hialine de l'atmosphère.

La beauté est un vice, merveilleux, de la forme.
\end{abstract}

César Moro, Amour à mort

Desde su publicación en 1988, Elogio de la madrastra de Mario Vargas Llosa ha provocado reacciones contrarias. Algunos lectores y criticos la han aplaudido como una lograda incursión del novelista peruano en el genero erótico ${ }^{1}$, mientras que otros han optado por ignorarla o la han considerado piedra de escándalo, hasta convertirse en argumento denigrante contra el escritor en la campaña presidencial peruana ${ }^{2}$. Entiendo que en los juicios esgrimidos han pesado excesivamente razones extraliterarias y se ha descuidado el análisis de la obra. Se olvidan las licencias que otorga la artificiosidad del arte, donde el hombre culto está acostumbrado a contemplar los amores entre Psiquis y Cupido, en cuyas representaciones plásticas se muestra la relación amorosa entre una mujer y un niño. Preguntado el autor por su relato en el Seminario "Creación

' Miguel García-Posada, Rafael Lampugnani, J. J. Armas Marcelo, etc.

${ }^{2}$ Alvaro Vargas Llosa, El diablo en campaña (Madrid:El País/Aguilar, 1991), 70. Beatriz de Moura (editora de la novela): "Elogio del hijastro", Asterisco cultural 5 (Publicación de la Fundación Germán Sánchez Ruipérez, Madrid, 1992), 12-13,

Recuerdo perfectamente que, en alguna de las entrevistas que le hicieron a Mario en el momento de la publicación de este libro, en junio de 1988, pocas semanas antes de que el viajara al Perú, ya tomada la grave decisión de preparar la campaña electoral a la presidencia de su pars, él dijo que Elogio de la madrastra no era un texto transgresor como habian podido ser los de Sade, Bataille o Klossowski, porque hoy en día todo estaba dicho y todo el mundo se habra hecho ya a las distintas manifestaciones del erotismo y la pornograffa, y que por lo tanto no habra motivo de escándaloen esta novela suya, que, en realidad, sólo se presentaba como una experiencia creativa muy personal inspirada en el impacto que algunos cuadros habłan producido en él. 
y Pensamiento en la Obra de Mario vargas Llosa"s, contestó definiéndolo como "divertimento", en el que se permitió la "exuberancia" del estilo frente a la contención de otras obras suyas; la narración habia surgido de las imágenes obsesivas de ciertos cuadros: Francis Bacon, Fernando de Szyszlo, Jacob Jordaens, que asociaba a sus reflexiones sobre los horrores del mundo del deseo y cómo la excitación sexual posee un componente imaginario. En el estudio psicoanalítico del relato, Rafael Lampugnani` puso de relieve cómo el tema de Elogio de la madrastra continuaba el de La tía Julia y el escribidor, con la venganza del padre a través de la seducción de la madrastra o tía en cada caso. Yo deseo dejar de lado los "demonios" personales del artista, para centrarme en la tradición literaria que precede la obra, como medio para ahondar en su factura y significación.

De acuerdo con declaraciones del propio autor, Vargas Llosa ha sido un entusiasta lector de literatura erótica, con especial interés por Georges Bataille (el incesto de Ma mère, los niños-adolescentes perversos de Historia del ojo), Pierre Klossowski. Asimismo ha gustado el mundo erótico de los libros de caballerías, con preferencia por Tirant lo Blanc de Joanot Martorell ${ }^{5}$. No obstante, Vargas Llosa ha afirmado sentir rechazo hacia el sexo puro en la escritura, así como a la ausencia total de tema erótico ${ }^{6}$. Esta última idea induce a pensar que Elogio de la madrastra puede ser algo más que una novelita de sexo, lo cual espero demostrar comparándola con un movimiento de la historia literaria hispánica: el Modernismo.

${ }^{3}$ Universidad Internacional Menéndez Pelayo, Sevilla, 30-9 a 4-10, 1991; supongo que las intervenciones del autor se recogerán en las actas del Seminario. Participé en él con la conferencia: "La problemática de la mujer en el teatro de Vargas Llosa" y allí tomé las notas que me han servido de base para este trabajo.

4 "Erotic Parricide in Vargas Llosa's Elogio de la madrastra", Antipodas, Journal of Hispanic Studies of the University of Auckland, Special Number MARIO VARGAS LLOSA, Editor Roy C. Boland, Number 1, December 1988: 209-218. Lampugnani aplica el método utilizado por Boland en su excelente Mario Vargas Llosa: Oedipus and the "Papa" State, Madrid: Editorial Voz 1990.

${ }^{5} \mathrm{El}$ interés por los dos escritores franceses, sobre todo Bataille, ha quedado plasmado en entrevistas, prólogos y artículos; Ver, por ejemplo, Contra viento y marea, 3 vols., Barcelona: Seix Barral, 1990. Otro tanto cabe decir de Martorell, basta recordar su "Carta de batalla por Tirant lo Blanc", recientemente integrada en el libro de igual nombre, Barcelona: Seix Barral, 1991.

6 Por ejemplo, La orgta perpetua, Barcelona: Bruguera, 1978, 25:

En multitud de ocasiones he reaccionado ante una historia de manera parecida: que una novela omita la experiencia sexual me irrita tanto como que reduzca la vida exclusivamente a la experiencia sexual (aunque esto último menos que lo primero, ya he dicho que entre irrealidades prefiero la más material).

"Ramera, filosofa y sentimental. La romana", La verdad de las mentiras. Ensayos sobre literatura, Barcelona: Seix Barral, 1990, 135-136:

La literatura exclusivamente erótica suele ser aburrida, una retórica en la que las variantes posibles de la experiencia amorosa se agotan pronto y comienzan a repetirse de manera 
El estado de la cuestión sobre el Modernismo tiende a evitar definirlo, aportando, en cambio, nociones acertadas para su caracterización ${ }^{7}$. Movimiento original, complejo, ecléctico, contradictorio, $y$, sin embargo, reconocible cuando tropezamos con sus manifestaciones. Analizaré Elogio de la madrastra a partir de los rasgos generalmente señalados para el Modernismo.

Según varios críticos ${ }^{8}$, la prosa modernista se caracteriza por el esmero con que se trabaja, que lleva a hablar de ella como prosa "artística", con "voluntad de estilo" o "calidad de página", por poseer cualidades hasta entonces vinculadas al verso. A la preocupación por el desarrollo de la trama de la novela decimonónica se opone una mayor atención a la estructuración y al lenguaje del relato modernista; de ahí el aumento de los géneros breves (crónica, cuento), en detrimento de la novela, que requiere un enorme esfuerzo para mantener el cuidado literario de principio a fin. Cuando Vargas Llosa califica su novela (en el sentido etimológico de la palabra "novela corta", novella) de "divertimento" y se refiere a la "exuberancia" del estilo, podemos pensar en una actitud de deleite formal análoga a la de los creadores de prosa modernista: máxime si comparamos esta obra con la gravedad de su restante producción narrativa, en la que intenta diseccionar los males del Pería ${ }^{9}$. Aquí no hay denuncias sociales o políticas, tan sólo elucubraciones sobre el comportamiento del individuo.

mecánica. Su sello caracterfstico es la monotonfa y comunicar una impresión de irrealidad, de fantasías desconectadas de la experiencia objetiva. Incluso Sade, en quien la recreación e interpretación obsesivamente sexual de la realidad tiene algo de genial, la mayor parte del tiempo, cuen te historias ofilos ofe, es anestésico. Ocurre que, escindido de su contexto, convertido en la única perspectiva para describir o inventar la realidad humana, el sexo se desencarna, se vuelve abstracto, una construcción intelectual en la que el lector dificilmente puede identificar su propia vivencia. Por eso, la literatura que sólo aspira a ser erotica está condenada, como el género policial o la ciencia ficción, a ser menor. No hay gran literatura erótica; o, mejor dicho, la gran litera tura nunca ha sido sólo erótica, aunque dudo que haya gran literatura que, además de otras cosas, no sea también erótica.

${ }^{7}$ La discusión acerca de la definición del Modernismo ha hecho correr ríos de tinta entre los críticos: Federico de Onís, Max Henríquez Ureña, Juan Ramón Jiménez, Guillermo Díaz Plaja, Pedro Salinas, Rafael Ferreres, Luis Monguio, Ricardo Gullón, Ivan A. Schulman, José Olivio Jiménez, Saúl Yurkievich, Alfredo A. Roggiano, Rafael Gutiérrez Girardot, Noé Jitrik, etc. Los modernistas se consideraban ante todo modernos, novedosos. ${ }^{8}$ Para el cotejo con los rasgos generales de la novela modernista empleo Ricardo Gullón, La novela lírica, Madrid: Cátedra, 1984; Anibal González, La novela modernista hispanoamericana, Madrid: Gredos, 1987; Donald Shaw, "La novela modernista", Historia dela literatura hispanoamericana, t. I: Del neoclasicismoal modernismo, Madrid: Cátedra, 1987, 507-513; Klaus Meyer-Minnemann, "La novela modernista hispanoamericana y la literatura europea del 'fin de siglo': puntos de contacto y diferencias", Nuevos asedios al Modernismo, edición de Ivan A. Schulman, Madrid: Taurus, 1987, 246-261.

${ }^{9}$ Realicé un extenso artículo titulado: "Articulación temática en la narrativa y teatro de Vargas Llosa. Visión del Peru”, que se encuentra actualmente en prensa. Entre los trabajos que adoptan este punto de vista cabe citar Marvin A. Lewis, From Lima to Leticia. The Peruvian Novels of Mario Vargas Llosa, Lanham, New York, London: University Press of America, 1983. 
Por otra parte, las palabras divertimento y exuberancia sugieren otros aspectos. El divertimento fue un género dramático o musical practicado sobre todo en el siglo XVIII. Como género teatral se caracteriza por su brevedad y movimiento, dado que sirve como interludio o entretenimiento entre actos de piezas más extensas. Como género musical, aparte de su consideración como ejercicio menor, se caracteriza por el uso de contrapunto; los divertimentos de Mozart son composiciones formadas por una serie de piezas subdivididas con breves intervalos ${ }^{10}$. Es posible que parezcan exageradas tantas precisiones, pero no podemos olvidar la cultura artística de un escritor admirador de Gustave Flaubert como Vargas Llosa. Si atendemos a la estructura de Elogio de la madrastra encontramos que se compone de 14 capitulos, separados entre sí a la manera impresionista de cuadros, en los que los monólogos interiores de los personajes y los planos de la acción central y su versión simbólica se suceden en forma de contrapunto, tenemos:

1. Lucrecia, acción central

2. Candaules (Rigoberto), version simbólica (S)

3. Rigoberto

4. Lucrecia

5. Diana (Lucrecia), $\mathrm{S}$

6. Rigoberto

7. Amor (Fonchito), $\mathrm{S}$

8. Lucrecia

9. Monstruo (Rigoberto), S

10. Rigoberto

11. Lucrecia

12. Laberinto de amor (Lucrecia), $\mathrm{S}$

13. Rigoberto

14. María con el ángel, $S$

El paralelismo interno de los capítulos en torno a dos tríos simbólicos de los personajes del triángulo amoroso se hace patente. El libro finaliza en un "Epílogo" desde el punto de vista de Justiniana, testigo de los hechos.

${ }^{10} \mathrm{~V}$., por ejemplo, Joseph T. Shipley, Diccionario de la Literatura Mundial. CríticaFormas-Técnica, Barcelona: Ediciones Destino, 1962; Patrice Pavis, Dictionnaire du Théâtre. Termes et concepts de l'analyse théatrale, Paris: Editions Sociales, 1980; Michael Brenet, Diccionario de la música, Barcelona:Ed. Beria, 1981. Agradezco al Sr. Marcelino Díez, Director de la Coral de la Universidad de Cádiz, su orientación en este punto. En el último diccionario citado, 175: "En el siglo XVIII se denominaban así las composiciones instrumentales del género de la serenata y de la casación, formados por pequeños fragmentos musicales de diversos movimientos, dos de los cuales, por lo menos, eran minuetos, y que se ejecutaban o bien al aire libre o como música de mesa durante un banquete principesco. Mozart escribio, de 1775 a 1777, seis divertimientos para pequeña orquesta de instrumentos de viento, destinados al servicio del Príncipe-Obispo de Salzburgo". 
La alternancia de puntos de vista produce el perspectivismo, pero permanece constante el narrador omnisciente que se introduce en los personajes tiñendo el relato de psicologismo. Los pormenores descriptivos y la interiorización de la acción a través de las reflexiones de los personajes, convierten el texto en una obra que Ricardo Gullón habría estudiado como novela lírica. El afán de mostrarnos los porqués de la actuación de los personajes conduce a la morosidad con que se desarrollan ciertos pasajes, como sucede con aquellos que corresponden a las abluciones de D. Rigoberto. Como novela erótica que es resulta explicable el sensualismo, pero no podemos olvidar que el impresionismo narrativo se distingue por "representar no las cosas y los sucesos, sino las sensaciones de los sucesos y de las cosas, su herida en un alma"11. Las imágenes visuales, auditivas, táctiles, olfativas y gustativas se multiplican; también el erotismo modernista exaltaba el goce de la carne sin el recato de épocas anteriores ${ }^{12}$. La plasticidad pictórica se refleja en la mención de colores -baste el ejemplo de la mancha blanca de la "grupa" que entusiasma a Candaules, a través del cuadro de Jacob Jordaens-y en el lujo oriental. Candaules y su esposa yacen en un "suntuoso bajel lleno de velámenes" (28), "hermosísimo lecho de columnas labradas, con escalinatas y cortinas de raso rojo, recargado de almohadillas, sedas y preciosos bordados" (35) y, en el mismo capítulo, para agasajar a Lucrecia, Candaules ha "cubierto sus cofres de alhajas y pedrerías" (30); D. Rigoberto imagina con horror a Lucrecia con "juna sedosa crin! -entre sus ebúrneos pechos" (43) y reflexiona sobre cómo la felicidad se encuentra "escondida, perla en su concha marina" (47) etc. ${ }^{13}$. Llaman la atención los juegos de la luz:

$\mathrm{Y}$ sus viejos temores sobre el niño comenzaron a evaporarse como una leve niebla corró́da por el sol del verano limeño. Había olvidado echarse encima la bata, iba desnuda bajo el ligero camisón de dormir de seda negra y sus formas blancas, ubérrimas, duras todavía, parecían flotar en la penu mbra entrecortada por los reflejos de la calle. Llevaba sueltos los largos cabellos y aún no se había quitado los pendientes, anillos y collares de la fiesta.

En el cuarto del niño - icierto, Foncho leía siempre hasta tardísimo! - había luz. Doña Lucrecia tocó con los nudillos y entró: 'AAlfonsito!' En el cono

\footnotetext{
${ }^{11}$ Amado Alonso, Ensayo sobre la novela historica. El modernismo en "La gloria de don Ramiro", Buenos Aires: Instituto de Filología, 1942, 152. Como es bien sabido, esta obra sirve de punto de partida en el estudio de la prosa modernista hispanoamericana. En 304306 Alonso definela novela modernista como "arte combinatorio", con elementos románticos, parnasianos, simbolistas, impresionistas y naturalistas. Hay reimpresión actual del libro de Alonso en Madrid: Gredos, 1984.

${ }^{12}$ Por ejemplo, Oscar Rivera-Rodas, "El discurso modernista y la dialéctica del erotismo y la castidad", Revista Iberoamericana 146-147, dedicado al modernismo (enero-junio 1989), 43-62.

${ }^{13}$ Cito Elogio dela madrastra por Barcelona:Tusquets, 1988. Otros ejemplos de sensibilidad modernista se encuentran en los capitulos "Diana después de su baño" y "Venus con amor y músican.
} 
amarillento que irradiaba la lamparilla del velador, de detrás de un libro de Alejandro Dumas, asomo, asustada, una carita de Niño Jesús (16).

El pastorcillo me iba siguiendo, embobado, tropezándose, sin apartar los ojos de $\mathrm{m}$ ni un instante. Mi favorita dice que cuando me vio, empinada - un rayo de sol encendiendo mis cabellos y enfureciendo mis pupilas, todos los músculos de mi cuerpo tirantes para disparar la flecha- el chiquillo rompió a llorar (70$71)^{14}$.

La exuberancia del estilo se puede entender asimismo como la elaboración de una prosa musical no exenta de amaneramiento. La disposición de los signos de puntuación y del vocabulario conforme a los acentos, el paralelismo y la repetición, la acumulación, la construcción binaria, el uso de términos sonoros, provoca tal efecto. D. Rigoberto describe las sensaciones que percibirán sus oídos, un rato más tarde, cuando pose su cabeza en el vientre de su esposa:

Allí no tendrían que esforzarse para sorprender la secreta música de Lucrecia, pues una verdadera sinfonia de sonidos líquidos y sólidos, prolongados y breves, difusos y nítidos, acudiría a revelarle su vida soterrada. Anticiṕ con gratitud cuánto lo emocionaría percibir, a través de esos órganos que ahora escarbaba con afecto prolijo, desembarazándolos de la película grasosa que se formaba en ellos cada cierto tiempo, algo de la existencia secreta de su cuerpo: glándulas, músculos, vasos sanguíneos, folículos, membranas, tejidos, filamentos, tubos, trompas, toda esa rica y sutil orografía biológica que yacía bajo la tersa epidermis del vientre de Lucrecia. [...] Y ya se ó́a susurrando, ciego de amor y de lujuria, las frases con que solía homenajear a su esposa mientras la acariciaba. "También esos ruiditos eres tú, Lucrecia; ellos son tu concierto, tu persona sonora" $(45-46)$.

Otro excelente ejemplo de sensaciones auditivas, que marca un compás de espera antes de las palabras con que Fonchito revela el triángulo amoroso a su padre:

Alfonso se rí́ a carcajadas, palmoteando, y don Rigoberto lo imito, divertido con la explosión de buen humor de su hijo. Un gato maulló a lo lejos. Pasó un automovil por la calle con la radio a todo volumen y durante unos segundos se oyeron las trompetas y maracas de una melodía tropical. Luego, surgio la voz de Justiniana, canturreando en el repostero, mientras accionaba la lavadora (168).

\footnotetext{
${ }^{14}$ La segunda cita evoca el comienzo de las Soledades de Góngora: "Era del año la estación florida/ en que el mentido robador de Europa/ (media luna las armas de su frente,/y el Sol todos los rayos de su pelo)// luciente honor del cielo,/ en campos de zafiro pace estrellas. Cito por la ed. de John Beverley, Madrid: Cátedra, 1987. En la conferencia de clausura que pronuncio el autor en el Seminario "Creación y Pensamiento en la Obra de Mario Vargas Llosa", dijo que durante la campaña presidencial peruana solía leer a Góngora; ignoro si esta lectu ra la había comenzado mientras redactaba Elogio de la madrastra. Hay más juegos de luz en las páginas $20,35,55,73,110,159,181,190-193$.
} 
D. Rigoberto rinde culto a la sensación gozando a su amada Lucrecia con los cinco sentidos, lo mismo que hacen las figuras paganas de Diana y Justiniana entre sí. El monstruo del cuadro de Bacon declara: "Tengo un olfato muy desarrollado y es por la nariz por donde más gozo y sufro" (122) y D. Rigoberto se atribuye a sí mismo la frase hiperbólica de Quevedo: "Erase un hombre a una nariz pegado" (129). Tras el enlace evidente, hay que subrayar la asociación que hace D. Rigoberto entre las sensaciones olfativas placenteras del amor y las nauseabundas de lo escatológico; dos mundos olorosos contrastados como los de musulmanes y cristianos en La gloria de don Ramiro ${ }^{15}$. Los efectos naturalistas que salpican la prosa modernista están principalmente en los capítulos de los cuadros de Bacon y Szyszlo, y en aquellos en que D. Rigoberto hace sus consideraciones sobre el excusado.

Uno de los recursos literarios más característicos del Modernismo son las transposiciones de arte, donde la realidad literaria gana prestigio por su referente cultural ${ }^{16}$. De esa manera el escritor modernista podía hacer gala de su cultura cosmopolita. Como he apuntado anteriormente, Elogio de la madrastra está estructurado a partir de varias transposiciones de arte, pues los capítulos simbólicos se refieren a sendos cuadros. Además, Lucrecia y Rigoberto darán origen a otras transposiciones de arte; Fonchito hace pensar a Lucrecia en un "Niño Jesús", "un ángel de nacimiento, uno de esos pajes de los grabados galantes que su marido escondía bajo cuatro llaves" (16-17). Como sucede también en el Modernismo, la mitología clásica ocupa un lugar importante: Candaules, rey de Lidia, Diana, Venus, Cupido. Por otra parte, los nombres naturales de los personajes de la novela poseen un valor simbólico: $\mathrm{D}$. Rigoberto ejecuta con rigor sus prácticas ablutorias y sexuales; Lucrecia lleva el nombre de la célebre matrona romana, pero también de Lucrecia Borgia, protagonista de una tragedia de Víctor Hugo en la que se plantea el incesto ${ }^{17}$; Justiniana, cuyo

\footnotetext{
${ }^{15}$ Lo destaca admirablemente Amado Alonso en su Ensayo sobre la novela historica.

${ }^{16}$ Entre los autores del boom Manuel Mujica Láinez sobresale por sus evocaciones culturales; es significativo el libro de George O. Schanzer: The Persistence of Human Passions: Manuel Mujica Lainez's Satirical Neo-modernism, London: Tamesis Books, 1986.

${ }^{17}$ He utilizado Víctor Hugo: Théatre, édition établie par Raymond Pouilliart, París, Garnier-Flammarion, 1979. Lucrecia Borgia va al encuentro de su hijo Genaro, quien ignora la identidad de sus padres; el encuentro provoca los celos del Duque de Ferrara, esposo de Lucrecia, quien cree a Genaro su amante e intenta asesinarlo. Finalmente, por accidente, Lucrecia envenena a Genaro que ha acudido a un convite con sus amigos y Genaro, en venganza, la apuñala; en ese momento Lucrecia revela su origen a Genaro. Hay que tener en cuenta que Víctor Hugo es uno de los autores más admirados por el escritor peruano; v., por ejemplo, Mario Vargas Llosa: "Los modelos literarios", Asterisco cultural 5 (Madrid: Fundación Germán Sánchez Ruipérez, 1992), 7-12. No he hallado un referente simbólico para Fonchito. Cuando le pregunté personalmente a Vargas Llosa sobre el tema, me contestó que no se había propuesto conscientemente dar valor simbolico a los nombres de los personajes, pero las asociaciones que propongo surgen fácilmente en cualquier lector culto.
} 
nombre evoca el del emperador de Oriente, es una observadora justa e imparcial del triángulo amoroso. En su reseña sobre la novela ${ }^{18}$ Miguel García-Posada señalaba acertadamente la importancia simbólica del unicornio, animal mitológico en el que se imagina transformado D. Rigoberto (94). Según el Diccionario de los símbolos dirigido por Jean Chevalier y Alain Gheerbrant ${ }^{19}$, el unicornio representa la fuerza, los grandes enamorados y la pureza. La ambigüedad de su interpretación permite entender de diferentes formas la alucinación de D. Rigoberto. Es sugestivo considerar que como símbolo de pureza el unicornio significa: "la flecha espiritual, el rayo solar, la espada de Dios, la revelación divina, la penetración de lo divino en la criatura. Representa en la iconografia cristiana la Virgen fecundada por el Espíritu Santo". Cuando D. Rigoberto se entera del triángulo amoroso, trata de engañarse a sí mismo pensando:

Sí, sí, ése era él. El anacoreta, el santón, el monje, el ángel, el arcángel que sopla la celeste trompeta y baja al huerto a traer la buena noticia a las santas muchachas (176-177).

$\mathrm{Y}$, a continuación, en el último capítulo, Vargas Llosa nos presenta el relato de una Anunciación que comienza "en medio de una luz rosada" (181). Sexo y virginidad se ofrecen como anverso y reverso de una moneda.

D. Rigoberto se comporta como un $d a n d y^{20}$, pues pretende hacer de su vida una obra de arte, de ahr sus exigencias a la hora de asearse y de hacer el amor con Lucrecia. El lecho conyugal es visto por él como su "espacio mágico" y cita el ensayo Homo ludens del historiador holandés Johan Huizinga (133) ${ }^{21}$. En este ámbito reducido de baño y alcoba donde él impone las normas, puede aspirar a alcanzar el ideal de perfección con que está obsesionado ${ }^{22}$; en este pequeño reducto se siente feliz, ajeno a los problemas cotidianos:

Esa era la virtud mágica del rito y los hombres primitivos lo habían descubierto en los albores de la historia: convertirlo a uno, por ciertos instantes eternos, en puro estar. El había redescubierto esa sabiduría a solas, por su cuenta y riesgo. Pensó: "La manera de sustraerse momentáneamente a la ruin decadencia y a las servidumbres edilicias de la civilidad, a las convenciones abyectas del rebaño, para alcanzar, por un breve paréntesis al día, una naturaleza soberana”. Pensó: "Esto es un anticipo de inmortalidad" (132).

${ }^{18} A B C$ de Madrid, suplemento literario, 25-6-1988.

${ }^{19}$ Barcelona: Editorial Herder, 1986.

${ }^{20}$ Hans Hinterhäuser, Fin de siglo. Figuras y mitos, Madrid: Taurus, 1980.

${ }^{21}$ En Homo ludens (1938) Huizinga analiza el papel del juego en la historia de la cultura. Para Huizinga el siglo XVIII se destaca por la abundancia de elementos lúdicos. He utilizado la edición de Madrid: Alianza, 1972.

$2247,79-80,83,93,173$. 


\begin{abstract}
Ahora la estaba sintiendo a su alrededor como una aureola y dentro de unos minutos él sería ella, y la dicha sería también su mujer con él y con ella, unidos en esa trinidad profunda de los dos que, gracias al placer, eran uno o mejor dicho tres. ¿Había resuelto, tal vez, el misterio de la Trinidad? Se sonrió: no era para tanto, cachafaz. Sólo una pequeña sabiduría para oponer un momentáneo antídoto a las frustraciones y contrariedades de que estaba adobada la existencia. Pensó: "La fantasía corroe la vida, gracias a Dios" (138).
\end{abstract}

D. Rigoberto se autoconvence de que así conseguirá escapar al paso del tiempo e imbuye estas ideas a Lucrecia; no en vano la novela comienza con el 40 cumpleaños de su esposa. El rito acompaña a Joanot Martorell en las vicisitudes de su vida y, según Johan Huizinga en El otoño de la Edad Media, es requisito indispensable para el hombre pre-renacentista que anhela una vida más bella ${ }^{23}$. D. Rigoberto es refinado como los dandies y no puede evitar tener horror a lo vulgar. En su mente aristocrática las orejas son "como las caracolas que llevan atrapada, en su laberinto de nácar, la música del mar", "Flores abiertas, élitros sensibles, auditorios para la música y los diálogos" (41-42). Embebido en tales consideraciones, no advierte la tragedia conyugal que se le avecina con la seducción de su amada Lucrecia por el niño; en este sentido muestra la psicología de los héroes de las novelas modernistas cuyos mundos imaginarios difieren de la realidad que los rodea, hasta que en un determinado momento chocan con ella y se acaban sus ilusiones. En definitiva, se trata de un fanático más cuyas obsesiones provocan su fracaso, como en otras novelas de Vargas Llosa ${ }^{24}$.

La predilección de los modernistas por el siglo XVIII francés hace preciso recordar que es la época de los libertinos célebres, por ejemplo, Sade y Casanova; la afición de D. Rigoberto por la literatura erótica concuerda con ello, igual que los cuadros de Boucher y Tiziano y la palabra divertimento. La teoría del "arte por el arte" que heredaron los modernistas sirve de fundamento a la amoralidad

${ }^{23}$ Por ejemplo, Vargas Llosa entrevistado por Ricardo Cano Gaviria en El buitre y el ave fénix, Barcelona: Editorial Anagrama, 1972, 53-55, habla de Martorell: "fue un hombre que, además de desafiar a todos esos personajes, fue sumamente puntilloso, minucioso, prolijo, y casi maniático, en las discusiones de tipo procesal relativas a los duelos. Siempre estaba creando complicaciones en lo que se refiere al rito, a las formas de combate. [...] La visión del mundo que hay en Martorell es esencialmente formal. La vida, para él, es fundamentalmente forma. [...] Las ceremonias rituales hasta cierto punto podían constituir la vida de un hombre; [...] En Tirant lo Blanc, a la vez que da un testimonio absolutamente maravilloso de las costumbres sociales, militares, eróticas y jurídicas de su época, construye un mundo donde las formas, en última instancia, deciden la esencia de los contenidos, y no a la inversa, como casi siempre ocurre en la realidad". J. Huizinga: $E l$ otoño de la Edad Media: Estudios sobre las formas de la vida y del esptritu durante los siglos XIVy XVen Francia y en los Patses Bajos, Buenos Aires: Revista de Occidente, 1947. ${ }^{24} \mathrm{~V}$., por ejemplo, el libro clásico de José Miguel Oviedo, Mario Vargas Llosa: la invención de una realidad, Barcelona: Barral Editores, 1977. 
o perversión que se les achaca. Los modernistas sostienen un ética de la belleza - léase ahora la cita de César Moro con que Vargas Llosa preludia Elogio de la madrastra y que reproduzco a inicio de este trabajo-, de ahí la libertad y el placer con que recrean la transgresión en sus obras. El escritor peruano se identifica con Bataille al pensar que: "la literatura puede expresar toda la experiencia humanal pero, fundamentalmente, expresa la 'parte maldita' de esa experiencia ${ }^{\text {m25 }}$; el arte viene a ser un ejercicio de catarsis para las aberraciones quellevamos dentro ${ }^{26}$. Es modernista la mezcla del erotismo con lo sagrado, que, si bien posee una larga tradición cultural, fue un modo de enfrentarse con el orden burgués de los artistas del Modernismo. Como explica Vargas Llosa, actualmente esa mezcla resulta más o menos indiferente para los no creyentes ${ }^{27}$, de tal forma que los pasajes atrevidos o blasfemos de Elogio de la madrastra tienen un aire anacrónico; por ejemplo:

Ella gimio, adolorida y gozosa, mientras, en un remolino confuso, divisaba una imagen de San Sebastián flechado, crucificado y empalado. Tenía la sensación de ser corneada en el centro del corazón (23).

Cada hemisferio es un paraíso carnal; [...] las firmes columnas de los muslos, me hacen pensar en un altar de esa religión bárbara de los babilonios que la nuestra borro (28).

"Déjame oír tus pechos", musitaria, [...] los escucharía con los ojos cerrados, reverente y extático, reconcentrado como en la elevación de la hostia (43-44). Etc. ${ }^{28}$.

${ }_{25}$ "Bataille o el rescate del mal", Contra viento y marea, II (1972-1983), Barcelona: Seix Barral, 1990, 21. Oviedo, op. cit., p. 329: "La novela es, para el, el terreno más fértil, más apto para practicar el querido acto nefando: la transgresión imaginaria de las normas establecidas, el ejercicio del $\mathrm{Mal}$ que el consenso social destierra, la victoria abominable del demonio sobre el ángel".

${ }^{26} \mathrm{~V}$., por ejemplo, Armando Pereira, La concepcion literaria de Mario Vargas Llosa, México: UNAM, 1981.

27 "Bataille o el rescate del mal", Contra viento y marea, $I I, 26$ :

Sus blasfemias, enormes, sólo pueden ser cabalmente a preciadas por el creyente; para quien no lo es resultan, a veces, disfuerzos, truculencias. [...] al incrédulo lo dejan frio y con un gusto de cosa pasada de moda entre los labios (26).

En "El placer glacial", ibid., 114:

Es preciso, para medir su atrevimiento, el desgarro que debió significar este libro para él, tener en cuenta que Bataille, en los años de Historia del ojo, era todavia católico o acababa de dejar de serlo. Para el hombre de nuestros dłas, indiferente en materia religiosa o católico "moderno" que se ha ido acostumbrando a ver cómo su antaño inexpugnable ciudadela de dogmas y tabúes, va siendo paulatinamente invadida por los enemigos del pasado -el compás y la escuadra, la hoz y el martillo, los demonios del sexo-, es diffil apreciar el poder revulsivo y la violencia moral de un episodio como aquél en el que el buen curita rubicundo de ojos de santo es masturbado, obligado a copular con Simone, y, por último, a beber sus orines en un cáliz y a eyacular en el copón de las hostias. Esta "enormidad" a los incrédulos de nuestros dras no les impresiona mucho más que los desaforados lamentos del monje loco de Lewis.

Si es, por tanto, igual el procedimiento entre los modernistas y Vargas Llosa, no lo es la intención.

${ }^{28}$ Otros ejemplos: $54,59,82-83,89,102-103,105,131-132,134,138,157-160,167,176$ 177. 
El pasaje con que culmina el erotismo blasfemo es el capítulo de la Anunciación (181-186). En dicho capítulo resulta ambigua la identidad simbólica del ángel: ¿la identidad anhelada por D. Rigoberto, tras haber conocido los extravios a los que contribuyeron sus teorías amorosas, tal como apunta la cita que reproduje anteriormente?, $\mathrm{o}, ¿$ Fonchito, el emisario del incesto, contrafigura del emisario de la máxima pureza en la Anunciación a María? El ángel posee "largas pestañas" (182) como Fonchito $(173,195)$ y la cabeza del niño perverso parece "circundada por un halo radiante" (167), "igual que una corona" (192). En muchos lugares de la novela Fonchito es comparado con un ser angélico ${ }^{29} \mathrm{y}$, cuando revela a su padre el incesto, éste piensa: "Así debía ser Luzbel" (175). La figura malvada que encubre sus fechorías con un aspecto bello está en la literatura de fin de siglo, baste recordar El retrato de Dorian Gray de Oscar Wilde. En medio de su exaltación amorosa, Lucrecia considera al niño su "spintria": "el niño que los pintores renacentistas añadían a las escenas de alcoba para que, en contraste con esa pureza, resultara más ardoroso el combate amatorio" (146); pero el repudio de D. Rigoberto deberá de abrirle los ojos a la realidad.

El enamoramiento que manifiesta el niño por una mujer madura resulta admisible para Justiniana (58), lo que favorece el engaño de Lucrecia. Los falsos melindres de Fonchito ante su madrastra, constituyen una versión paródica de la hipersensibilidad del protagonista de $E l$ niño que enloqueció de amor de Eduardo Barrios ${ }^{30}$. Ciertos críticos han señalado que en Elogio de la madrastra se muestra la infancia como una edad donde los niños no son tan inocentes como creemos $^{31}$, idea que contrasta con las de otras novelas de Vargas Llosa, en las que se ha visto como tema la nostalgia de la inocencia perdida y la corrupción de los adolescentes ${ }^{32}$. El niño, que debería de ser el elemento receptor en el hogar familiar, se convierte en manipulador y verdugo de las víctimas ingenuas que son sus padres. La que sale peor parada de la situación es Lucrecia, la madrastra, quien al principio reconoce: "Este niño me está corrompiendo" (64).

${ }^{29} 16,17,22,54,59,97,117,167,190,195$.

${ }^{30}$ A pesar de ser poco recordada hoy, esa novelita de Barrios obtuvo un gran éxito; he utilizado la edición de Buenos Aires: Losada, 1976. Luis Alberto Sánchez en Proceso y contenido de la novela hispano-americana, Madrid: Gredos, 1976, 252, la califica de "pequeña obra maestra, de intensa finura introspectiva".

${ }^{31}$ Rafael Lampugnani, Miguel García-Posada, op. cit.; David Sobrevilla, "La nueva teoría de la novela de Mario Vargas Llosa" Cuadernos Hispanoamericanos 496, octubre 1991, 71: "En el caso de Elogio de la madrastra (1988) la tesis que expresa esta nouvelle quizá se pueda proponer refraseando el epígrafe de Paul Nizan empleado por Vargas Llosa en la segunda parte de La ciudad y los perros: los niños y adolescentes no son tan ingenuos, "puros" y candorosos como a veces se cree.

${ }^{32}$ Por ejemplo, Jorge Edwards, "El gusano de la conciencia", Homenaje a Mario Vargas Llosa. Variaciones interpretativas en torno a su obra, Editores: Helmy F. Giacoman-José Miguel Oviedo, New York: Las Americas Publishing Company, 1971, 295-301; José Luis Martín, La narrativa de Vargas Llosa. Acercamiento estiltstico, Madrid: Gredos, 1974. 
Para ella la aventura con Fonchito es una "educación sentimental" a tono con las teorías de D. Rigoberto. Sale a relucir el machismo de la sociedad, pues tanto Rigoberto como Fonchito utilizan a Lucrecia a su antojo. Los caprichos del esposo son órdenes para la mujer sumisa: en el capítulo en que Lucrecia aparece transformada en Venus, Amor comenta:

Se trata, pues, de una dama dócil a la voluntad de su dueño, como debe serlo la esposa cristiana, de modo que, si hay pecado en estos ágapes sensuales, es de suponer que ennegrecerán únicamente el alma de quien, para su deleite personal, los concibe y los manda (103).

De igual manera, figura como víctima propiciatoria en la explicación del cuadro de Fernando de Szyszlo. Contrástese este comportamiento con el dominio de la situación en el lesbianismo de Diana (Lucrecia) y Justiniana, que podrían suscribir feministas radicales; en la Antigüedad clásica Diana era la diosa virgen. La liberación de prejuicios de Lucrecia tras mantener relaciones sexuales con Fonchito, la hace pasar de espectadora de los acertijos de D. Rigoberto, quien le asigna un papel y le pregunta continuamente “QQuién soy?”, a creadora de su propio acertijo ${ }^{33}$; piensa entonces "He conquistado la soberanía", pero -comenta el narrador- "no hubiera podido precisar de qué" (146).

A pesar de que en la novela erótica el sexo tiende a presentarse como un valor absoluto, en Elogio de la madrastra Vargas Llosa sugiere lo contrario. Los paraísos artificiales del individuo resultan insuficientes para afrontar la existencia. D. Rigoberto antes del desenlace:

De joven había sido militante entusiasta de Acción Catolica y soñado con cambiar el mundo. Pronto comprendió que, como todos los ideales colectivos, aquél era un sueño imposible, condenado al fracaso. Su espíritu práctico lo indujo a no malgastar el tiempo librando batallas que tarde o temprano iba a perder. Entonces, conjeturo que el ideal de perfección acaso era posible para el individuo aislado, constreñido a una esfera limitada en el espacio (el aseo o santidad corporal, por ejemplo, o la práctica erótica) y en el tiempo (las abluciones y esparcimientos nocturnos de antes de dormir) (80).

Le restaba aún completar las tareas invariables del rito: boca y axilas. Aunque se concentraba en ellas con sus cinco sentidos, tomándose todo el tiempo debido para asegurar el éxito de la operación, dominaba de tal modo el ritual que su atención podía escindirse y parcialmente consagrarse, también, a un principio de estetica, uno distinto cada día de la semana, uno extraído de aquel manual, tabla o mandamientos elaborados por él mismo, también secretamente, en estos enclaves nocturnos que, bajo la coartada del aseo, constituran su religión particular y su personal manera de materializar la utopia (89). ${ }^{39}$ Huizinga en Homo ludens resalta la manifestación de poder que encierran los enigmas;
en este caso con ellos los amantes se ponen a prueba mutuamente. 
D. Rigoberto cavila: "Todo lo que brilla es feo $y$, principalmente, los hombres brillantes" (p. 89, con un juego de palabras). La conversión del sexo en absoluto hace olvidar otros valores; Lucrecia, después de haber sido seducida por Fonchito:

\begin{abstract}
Se ha suspendido el tiempo, por supuesto. Alli no envejeceremos ni moriremos. [...]

Han sido abolidos también los sentimientos altruistas, la metafísica y la historia, el raciócinio neutro, los impulsos y obras de bien, la solidaridad hacia la especie, el idealismo civico, la simpatía por el congénere; han sido borrados todos los humanos que no seamos tú y yo. Ha desaparecido todo lo que hubiera podido distraernos o empobrecernos a la hora del egoísmo supremo que es la del amor. Aquí nada nos frena ni inhibe, como al monstruo y al dios. [...]

Eramos una mujer y un hombre y ahora somos eyaculación, orgasmo y una idea fija. Nos hemos vuelto sagrados y obsesivos (159-160).
\end{abstract}

La asociación del relato a los cuadros de Francis Bacon y Fernando de Szyszlo, plantea la relación entre sexo y violencia, los horrores que puede desencadenar el mundo del deseo $0^{34}$. Una vez más el escritor serio que es Vargas Llosa no ha podido evitar hacernos participes de sus preocupaciones.

He enfocado el trabajo señalando los parecidos evidentes entre Elogio de la madrastra y el Modernismo; ahora bien, ¿se trata sólo de coincidencias o pudo haber algún momento en que Vargas Llosa leyera a los escritores de fin de siglo? D. Rigoberto ostenta en su biblioteca la colección "Les maîtres de l'amour" dirigida y prologada por Guillaume Apollinaire (165), la misma que Vargas Llosa leyó cuando trabajaba en la Biblioteca del Club Nacional de Lima; por eso Juan Armas Marcelo imagina a D. Rigoberto un señor de la clase alta criolla, como los afiliados al Club Nacional ${ }^{35}$. Al margen de esa colección, es posible que la Biblioteca del Club Nacional contara con autores modernistas leídos como autores pornográficos, pongo el ejemplo de José María Vargas Vila. En "Madrid cuando era aldea"36, Vargas Llosa asistió a clases de Literatura Hispanoamericana en la Universidad Complutense y, según dice y es fácil confirmarlo, la Literatura Hispanoamericana se estudiaba hasta el Modernismo. En la novela que comentamos cita irónicamente a José María Eguren (129) y

\footnotetext{
${ }^{34}$ "El placer glacial", Contra viento y marea, II, 128: "En cuanto a la índole de ese material obsesivo no hay nada que la literatura maldita no hubiera revelado anteriormente ni demostración que no fuera ilustrada, digamos, por un Sade, de que, que, como lo muestra Historia del ojo, el deseo en libertad conduce a la destrucción y autodestrucción, que la violencia es ingrediente del sexo y viceversa y que la esperma tarde o temprano se torna sangre".

${ }^{35}$ Entrevista a Vargas Llosa por Ricardo Cano Gaviria, 107; J. J. Armas Marcelo, "Elogio de 'las partes malditas'(1988)" Vargas Llosa. El viciode escribir, Madrid:Ediciones Temas de Hoy, 1991.

${ }^{36}$ Contra viento y marea, III (1964-1988), Barcelona: Seix Barral, 1990, 9-13.
} 
todos conocemos la devoción que siente Vargas Llosa por Flaubert, cuyos lazos con la prosa modernista hispanoamericana han sido destacados por Aníbal González ${ }^{37}$. Siempre es interesante analizar los influjos de otras lenguas en las letras hispanoamericanas, pero no podemos olvidar atender asimismo a la propia tradición.

${ }^{37}$ "Flaubert y la novela modernista", op. cit. S6lo mencionar Mario Vargas Llosa, La orgía perpetua (1975). 